\title{
One's sex, sleep, and posttraumatic stress disorder
}

\author{
Ihori Kobayashi ${ }^{1 *}$, Nancy Cowdin ${ }^{1,2}$ and Thomas A Mellman ${ }^{1}$
}

\begin{abstract}
Women are approximately twice as likely as men to develop posttraumatic stress disorder (PTSD) after trauma exposure. Mechanisms underlying this difference are not well understood. Although sleep is recognized to have a critical role in PTSD and physical and psychological health more generally, research into the role of sleep in PTSD sex differences has been only recent. In this article, we review both animal and human studies relevant to sex differences in sleep and PTSD with an emphasis on the roles of sex hormones. Sleep impairment including insomnia, trauma-related nightmares, and rapid-eye-movement (REM) sleep fragmentation has been observed in individuals with chronic and developing PTSD, suggesting that sleep impairment is a characteristic of PTSD and a risk factor for its development. Preliminary findings suggested sex specific patterns of sleep alterations in developing and established PTSD. Sleep maintenance impairment in the aftermath of trauma was observed in women who subsequently developed PTSD, and greater REM sleep fragmentation soon after trauma was associated with developing PTSD in both sexes. In chronic PTSD, reduced deep sleep has been found only in men, and impaired sleep initiation and maintenance with PTSD have been found in both sexes. A limited number of studies with small samples have shown that sex hormones and their fluctuations over the menstrual cycle influenced sleep as well as fear extinction, a process hypothesized to be critical to the pathogenesis of PTSD. To further elucidate the possible relationship between the sex specific patterns of PTSD-related sleep alterations and the sexually dimorphic risk for PTSD, future studies with larger samples should comprehensively examine effects of sex hormones and the menstrual cycle on sleep responses to trauma and the risk/resilience for PTSD utilizing various methodologies including fear conditioning and extinction paradigms and animal models.
\end{abstract}

Keywords: Posttraumatic stress disorder, PTSD, Sleep, Sex differences

\section{Review}

Posttraumatic stress disorder (PTSD) is a psychiatric condition that develops in some individuals after experiencing events involving threat of injury, physical integrity, or death [1]. Approximately $8 \%$ of adults in the U.S. meet diagnostic criteria for PTSD at some point in their lives [2]. PTSD consists of three clusters of symptoms: re-experiencing (e.g., recurrent nightmares about trauma, flashbacks), avoidance (e.g., avoidance of trauma reminders), and hyperarousal (e.g., insomnia, hypervigilance) [1]. In addition to these potentially debilitating symptoms, individuals with PTSD are at greater risk for other mental and physical health problems

\footnotetext{
* Correspondence: ihori.kobayashi@howard.edu

'Department of Psychiatry, Howard University, 530 College St. NW Washington, DC 20060, USA

Full list of author information is available at the end of the article
}

including suicidal behaviors, cardiovascular diseases, and gastrointestinal diseases [1,3-5].

Women have a higher lifetime prevalence of PTSD (10\% in women vs. $5 \%$ in men) as well as a greater risk of developing PTSD following trauma exposure (13-20\% vs. 6-8\%), even though men have a higher risk for exposure to traumatic events (51\% vs. $61 \%)$ [2,6]. A possible explanation for this sex difference is women's higher risk for exposure to traumatic events associated with a greater risk of developing PTSD such as rape and molestation [2]. However, a meta-analysis conducted by Tolin and Foa [7] revealed women's higher susceptibility to PTSD even after controlling for type of trauma, especially following exposure to trauma more frequently experienced by men (e.g., accidents, nonsexual assaults). They, therefore, concluded that trauma type is not the only factor contributing to the women's greater risk of

\section{Biomed Central}


developing PTSD [7]. However, this analysis by category of trauma may not be sensitive to differences in the nature of assaults. Women are more likely to be exposed to more persistent assaults such as in the case of domestic violence than men [8], which may have influenced the women's greater susceptibility. Although the metaanalysis showed slightly higher risks for PTSD in women following exposure to combats, it is important to note that recent studies examining veterans of recent wars in Iraq and Afghanistan have revealed small sex differences in combat exposure and no differences in the risk of developing PTSD after controlling for levels of combat exposure $[9,10]$.

Various psychosocial and biological factors have been hypothesized to contribute to the sex differences in the risk for PTSD (see Olff, Langeland, Draijer, \& Gersons, 2007 [11] for a review). Sleep has been recognized to play a critical role in PTSD (see the Sleep in PTSD section) as well as other mental and physical conditions (see the next section). Despite this, the role of sleep in the sexually dimorphic risk for PTSD has only recently begun to be investigated. In this article, we first review the role of sleep in physical and psychological health and in PTSD, and then we review sex differences and the roles of sex steroids in PTSD and sleep. Finally we present limited available findings and perspectives in the area of sex differences in PTSD-related sleep disturbance.

\section{Sleep and physical and psychological health}

Relationships between sleep and physical health have been documented in a number of prospective and crosssectional studies. Long and short sleep durations in contrast to 7-8 hours of habitual sleep are associated with higher mortality rates [12] and higher risk for coronary heart disease related events [13] and weight gain [14]. Sleep has also been linked to the chronic activation of immune function $[15,16]$. Experimental sleep restriction increased secretion of interleukin 6 and tumor necrosis factor- $\alpha[17,18]$. Elevated basal levels of these proinflammatory cytokines were also observed in obstructive sleep apnea patients [19].

Subjective sleep disturbances predicted the onset of depressive symptoms in a general population, the elderly with a history of depression, and patients with bipolar disorder [20-22]. In an elderly group that received treatment for depression, greater subjective sleep impairment, less stage 2 sleep (N2), greater rapid-eye-movement (REM) sleep and REM activity before treatment were associated with slower recovery [23]. In contrast, a prospective study examining individuals going through divorce found that lower eye-movement density during the first REM episode at the beginning of their divorce process predicted more depressive symptoms one year later [24].

\section{Sleep in PTSD}

Difficulty falling and staying asleep and recurrent trauma-related nightmares are two of the 17 diagnostic criteria for PTSD [1]. Individuals with PTSD are more likely to report these sleep disturbances than traumaexposed individuals without PTSD [25,26]. For example, $91 \%$ of Vietnam veterans and $73 \%$ of rape or attempted rape victims with PTSD reported sleep initiation or maintenance problems as opposed to $62.5 \%$ and $18 \%$ of similarly exposed comparison subjects without PTSD, respectively $[25,27]$. Similarly, 38 to $73 \%$ of individuals with PTSD across studies reported experiencing recurrent nightmares about trauma, whereas only 6 to $12 \%$ of trauma-exposed individuals without PTSD reported having nightmares $[25,27,28]$. These sleep disturbances were also observed in individuals at greater risk for PTSD. Prospective studies showed that insomnia immediately prior to trauma exposure and soon after trauma predicted the subsequent development of PTSD $[29,30]$. In addition, the presence of trauma-related nightmares within a month of serious injury predicted PTSD symptoms severity at 6-weeks and 1-year post-injury [31,32].

In contrast to the consistently reported subjective sleep disturbances in PTSD, results of studies using polysomnography (PSG) are mixed, with some studies not finding differences between individuals with and without PTSD and the other studies documenting PTSD-related sleep impairments [33]. Overestimation of sleep impairments by people with PTSD has been suggested as a possible explanation for the discrepancies between subjective and objective sleep in PTSD [34]; however, the overestimation hypothesis has not been supported by several studies that evaluated relationships between subjective and objective sleep in PTSD [35-37]. A metaanalytic review of PSG studies revealed small effect sizes indicating that people with PTSD have more stage 1 sleep (N1) and less slow wave sleep (SWS), collectively indicating shallower sleep, than those without PTSD [33]. More consistent PSG findings exist regarding REM sleep activity and fragmentation. The meta-analysis found a medium-size effect of increased REM eye-movement density in PTSD. Individuals with chronic PTSD have exhibited signs of REM sleep interruption including a greater number of entries to $\mathrm{N} 1$ or wake from REM sleep or an increased percentage of $\mathrm{N} 1$ or wake during REM periods [38,39]. REM sleep fragmentation in the aftermath of trauma may also predict or have a role in the development of PTSD. A prospective study found a greater number of REM periods and shorter duration of continuous REM segments within a month of serious injury in patients who subsequently developed PTSD compared to injured patients who did not develop PTSD despite similar overall sleep maintenance and duration [40]. 
In the past decade, quantitative electroencephalography analysis (qEEG) has begun to be utilized in the field of sleep research, and a limited number of qEEG studies have been conducted in PTSD. In a lab-based PSG study, Woodward and colleagues [41] found reduced low-frequency [i.e., delta $(0.2-3.8 \mathrm{~Hz})$ and theta $(4-7.8 \mathrm{~Hz})]$ spectral power during SWS in male combat veterans with PTSD as compared to male veterans without PTSD even though no group difference was found in the percentage of traditionally scored SWS. However, Germain and colleague's home PSG study with small samples $[\mathrm{n}=10$ (3 men) for PTSD and 5 ( 2 men) for control groups] [42] found increased delta $(0.2-4 \mathrm{~Hz})$ power during the entire sleep period in violent crime victims with PTSD compared to healthy controls. Germain and colleagues suggested that this result indicates increased sleep pressure induced by chronic sleep disruption in PTSD. Beta activity is considered a marker of cortical arousal $[43,44]$, and alterations of beta spectral power in PTSD has been reported. Increased beta power $(20-32 \mathrm{~Hz})$ during the entire sleep period in PTSD was observed in the home PSG study, but less beta power during REM sleep in veterans $(\mathrm{N}=29,1$ woman) with chronic PTSD $(\mathrm{n}=16)$ compared to veterans without PTSD $(n=13)$ was reported in a lab-based PSG study [45]. In recently trauma-exposed individuals, reduced relative beta power $(14-32 \mathrm{~Hz})$ during REM sleep was associated with more severe PTSD symptoms and nightmares [46].

A role for REM sleep alteration is suggested by animal models of PTSD sleep disturbance that utilize fear conditioning. Male mice and rats exhibited reduced REM sleep and total sleep time (TST) during light phases (when mice and rats normally sleep) immediately following the footshock training [47-50]. In addition, reexposure to cues and contexts paired with footshocks induced alteration in REM sleep including reduced REM sleep and REM segments duration in rats and mice $[47,51,52]$ for as long as 34 days after the training [53]. Genetic factors seem to influence the susceptibility to REM sleep alterations following shock training and reexposure to conditioned cues. The greater REM sleep suppression following footshock training was observed in stress-reactive $\mathrm{BALB} / \mathrm{cJ}$ mice compared to the less reactive C57BL/6 J mice [47,54]. Re-exposure to conditioned cues fragmented REM sleep in stress-sensitive Wistar-Kyoto rats, but consolidated REM sleep in less sensitive Wister rats [55].

In summary, subjective reports of insomnia and trauma-related nightmares are common among people with PTSD. These sleep disturbances were also reported immediately before and after trauma exposure by people who developed PTSD, suggesting sleep disturbances increase the vulnerability for PTSD. However, it is also possible that these associations are a consequence of common risk factors. Although PSG studies inconsistently documented disturbances in sleep initiation and maintenance and sleep depth in PTSD, disrupted REM sleep has more consistently been reported. REM sleep fragmentation was found in individuals with chronic PTSD as well as recently traumatized people who subsequently developed PTSD. Analogous alterations of REM sleep were observed in rats and mice following exposure to footshocks and re-exposure to cues previously paired with footshocks. Strain comparisons revealed genetic influence on susceptibility to REM sleep disturbances following exposure to footshocks and stress cues. These findings of animal and human studies suggest that REM sleep disruption is not only a characteristic of established PTSD, but also a contributor to the development of PTSD.

\section{Sex differences in sleep}

Given the role of sleep in PTSD, it is possible that sex differences in sleep contribute to the increased prevalence in women. In the general population, women across the adult age span are more likely than men to report having sleep initiation and maintenance problems, as well as nightmares [56-59]. However, PSG studies of the general population and healthy volunteers have shown that women have better sleep continuity indexed by less wake after sleep onset (WASO), higher sleep efficiency (SE), and deeper sleep as indicated by a lower percentage of N1 and higher percentage of SWS [60-62]. Women experience fewer respiratory disturbances during sleep; however, the sex differences in sleep impairment persisted after controlling for sleep-related respiratory disturbances $[60,61,63]$.

Sex hormones and their fluctuations throughout the menstrual cycle likely contribute to the paradoxical relationship between sex and subjective/objective sleep. Female sex hormones have sleep-promoting effects when they are exogenously administered. Administration of progesterone to men increased non-REM sleep, and estrogen replacement improved sleep initiation and maintenance in hypogonadal and perimenopausal women [64]. In contrast to the sleep promoting effects of female sex hormones, exogenous administration of testosterone to men induced obstructive sleep apnea symptoms and reduced TST. Testosterone replacement increased REM sleep in hypogonadal men $[65,66]$.

Women report greater subjective sleep disturbances and lowered sleep quality during the late-luteal phase when both estrogen and progesterone are declining and menstruation when both the hormones are low compared to the mid-follicular phase when estrogen is rising and progesterone is low $[67,68]$. Objective sleep changes across the menstrual cycle have been examined in PSG 
studies with small samples of healthy, naturally cycling women $(N s=5-18)$. Preliminary results of those studies include shallower sleep, longer sleep onset latency (SOL), and altered REM sleep mostly during the mid- or lateluteal phase when progesterone is high and estrogen is moderate (mid-luteal) or both hormones are decreasing (late-luteal) compared to the mid-follicular phase [69-71]. The findings related to REM sleep include lower percentage of REM sleep in the late and mid-luteal phase, shorter REM period duration in the mid-luteal phase, and longer REM latency in the late-luteal phase compared to the mid-follicular phase [69,71]. In addition, qEEG revealed increased spectral power of sleep spindle frequency in the late-luteal phase compared to the late-follicular phase [72] and increased spectral power of the upper sleep spindle frequency range $(14.25-15.0 \mathrm{~Hz})$ during non-REM sleep in the luteal phase compared to the follicular phase [70]. However, it is important to note that findings of PSG studies are not entirely consistent. Three PSG studies with small samples $(N s<10)$ did not detect differences in indices of sleep initiation, maintenance, or depth between the follicular and luteal phases [69,73,74].

Effects of exogenous and endogenous sex hormones on sleep were also found in animals, mainly during dark periods when they are normally active. Intact female (estrous cycle not controlled) C57BL/6 J mice had more wake time and less non-REM sleep during dark periods, but not during light periods, compared to intact males [75]. The differences in either wake or non-REM sleep were not observed between gonadectomized male and female mice. In Sprangue-Dawley rats, intact males had more REM sleep compared to intact females (estrous cycle not controlled) in both light and dark periods, and ovariectomy increased REM sleep during dark periods, but not during light periods [76]. In contrast with human studies, sleep suppressing effects of estradiol and sleep promoting effects of testosterone were observed in mice, although these effects were observed mainly during dark periods. Estradiol administration to ovariectomized female C57BL/6 J mice increased wake time and reduced both non-REM and REM sleep during dark periods, but testosterone administration to castrated male mice reduced wake time and increased non-REM sleep during dark periods [77]. These effects were not observed during light periods. In both Sprangue-Dawley and C57BL/6 J mice, increased REM sleep during dark periods was observed during the diestrus phase when both estradiol and progesterone levels are low compared to other estrous phases [76,78], although results have varied depending on strains of animals. Estrous cycle-related change in sleep was not found in BALB/cJ mice, but reduced light period REM and non-REM sleep were found during the diestrus phase compared to other phases in $\mathrm{C} 3 \mathrm{H} / \mathrm{HeJ}$ mice [78].
In summary, women report greater subjective sleep disturbances than men; however, in PSG studies, women typically sleep better than men. Effects of sex hormones and the menstrual/estrous cycle on sleep have been found in both human and animals, although the directions and timing (i.e., active or sleep periods) of effects differ by species. In humans, exogenously administered estrogen and progesterone promoted sleep; however, in the luteal phase when progesterone levels are high, women had shallower and more disrupted sleep and decreased and more fragmented REM sleep compared to the follicular phase when progesterone is low. In rats and some strains of mice, sleep suppressing effects of exogenous and endogenous female sex hormones were observed during dark periods when the animals are normally active. These findings underscore the importance of taking into account effects of sex hormones and the menstrual cycle in investigation of sex differences in sleep. The differences in results of animal and human studies warrant caution in using animal models to examine effects of exogenous sex hormones on human nighttime sleep.

\section{Roles of Sex hormones in the development of PTSD}

There have been only a few human and animal studies that explored the roles of sex hormones in PTSD. Those studies utilized fear-conditioning and fear-extinction paradigms, as impairment in a fear-extinction process has been hypothesized to be critical to the pathogenesis of PTSD [75]. Milad and colleagues [79] found that men and women in the early-follicular phase, when both estrogen and progesterone levels are low, had greater retention of extinction memory measured by skin conductance compared to women in the late-follicular phase when estrogen is high. In animal studies, male and ovariectomized female rats showed slower extinction than intact female rats [80], and female rats in the proestrus phase, when both estrogen and progesterone are high, exhibited less freezing behaviors at the end of fear conditioning training and during extinction [81]. These findings suggest that sex hormones play a role in the fearextinction process. Similar to the effects of exogenous sex hormones on sleep, the direction of effects may be different between humans and animals; however, the differences in measures used in human and animal studies (i.e., skin conductance vs. freezing; extinction recall vs. fear conditioning training and extinction) make the comparison of results difficult. Further investigation using the same measures is needed to elucidate directions of the effects.

\section{Sex differences in PTSD-related sleep disturbances}

Only a limited number of studies have directly compared men's and women's subjective or objective sleep in PTSD. 
A study examining subjective sleep in chronic PTSD did not find sex differences (190 women and 177 men) in sleep reported in a sleep questionnaire [82]. As mentioned earlier, fragmented REM sleep was observed in individuals with chronic PTSD and developing PTSD [38-40]. A preliminary finding of a PSG study with a small number of participants suggested greater REM sleep fragmentation indexed by higher number of REM segments in men with PTSD $(n=3)$ compared to women with PTSD $(n=14)$ [83]. This study did not examine sex differences in other sleep parameters. A secondary analysis of the aforementioned prospective study examining PSG sleep in the aftermath of serious injuries found that REM sleep fragmentation indexed by the shorter duration of REM segments soon after trauma was associated with the development of PTSD in both sexes [40,84]. However, the REM fragmentation might be more pronounced in women than men as the effect size was greater in women [Cohen's $d=-0.6$ for men $(n=10$ for PTSD, 12 for non-PTSD groups), $d=-1.1$ for women ( $n=6$ for PTSD, and 7 for non-PTSD groups)]. The secondary analysis found sex differences in indices of overall sleep maintenance. Women who developed PTSD had longer WASO and less TST compared to men who developed PTSD and women who did not develop PTSD, respectively. Contrary to expectations, better sleep continuity indexed by shorter WASO was found in men who developed PTSD compared to men who did not develop the disorder. As both the PSG studies examining sex differences in established and developing PTSD had a small number of participants, results should be considered preliminary.

The aforementioned meta-analysis of PSG studies performed subgroup analyses with studies consisting of only male participants (13 studies) [33]. Results revealed less TST and SWS, more N1, and longer SOL in PTSD compared to controls. Only two studies have investigated PTSD-related objective sleep impairment with only female participants, and those studies revealed less TST and N2 measured by PSG and longer SOL and more movements measured by actigraphy in women with PTSD compared to women without PTSD $[36,85]$. However, these apparent PTSD-related sleep alterations found in the studies with only men and only women could be influenced by other sex-related factors such as the use of substances. Roles of sex hormones or the menstrual cycle in PTSD-related sleep impairment have not been investigated in human or animal studies.

In summary, only a few studies with a small number of participants have directly investigated sex differences in PTSD-related sleep alteration. Although fragmented REM sleep in the aftermath of trauma was associated with the development of PTSD in both sexes, the association might be stronger in women. Sleep maintenance impairment soon after trauma might be associated with the development of PTSD in women. Results of studies examining objective sleep of either men or women have revealed differences and similarities in PTSD-related sleep disturbances between sexes. Reduced deep sleep has been found in studies with only men, and impaired sleep initiation and maintenance with PTSD have been found in both studies with only men and only women. The role of sex hormones and the menstrual cycle on the PTSDrelated sleep disturbances have not been studied.

\section{Conclusions}

Research of chronic and developing PTSD has revealed that sleep impairment is a characteristic of PTSD and a risk factor for the development of PTSD, although the associations may also be related to common risk factors. Sex differences in the risk of developing PTSD following trauma exposure have been well documented; however, investigation into roles of sleep in the sex difference has only recently begun. Although recent preliminary evidence points to sex specific patterns of sleep impairment related to chronic and developing PTSD, mechanisms connecting the sex specific patterns and the development and maintenance of PTSD have not been investigated. The effects of sex hormones and the menstrual cycle on sleep and PTSD add complexity to the efforts to elucidate the mechanisms. Investigation of the roles of sex hormones in the development of PTSD and post-trauma sleep in trauma-exposed individuals entails methodological challenges (e.g., recruitment of recently traumatized individuals and measuring sex hormones and monitoring the menstrual cycle in the aftermath of trauma) and has not been conducted. The use of fearconditioning and extinction paradigms may circumvent some of the methodological challenges and will yield information leading to further understanding of the roles of sex hormones in the development of PTSD. Animal PSG studies showed that exposure to footshock stress reduced REM sleep and the duration of REM segments $[47,51,52]$. Involvement of sex hormones in the fear extinction process was also suggested in animal and human fear-conditioning studies using skin conductance and freezing behaviors as outcome measures, respectively [79-81]. Future studies should examine effects of sex hormones and the menstrual/estrous cycle on sleep responses to fear-conditioning and extinction processes. Incorporation of neurohistological, neuroimaging, and qEEG methods in those studies would further elucidate mechanisms underlying sex differences in sleep and PTSD.

\section{Abbreviations}

PTSD: Posttraumatic stress disorder; PSG: Polysomnography; REM: Rapid eye movement; EEG: Electroencephalogram; qEEG: Quantitative electroencephalography analysis; WASO: Wake after sleep onset; 
SOL: Sleep onset latency; SE: Sleep efficiency; TST: Total sleep time; TIB: Time in bed; SWS: Slow wave sleep; N1: Stage 1 sleep; N2: Stage 2 sleep.

\section{Competing interests}

The authors declare that they have no competing interests.

\section{Authors' contributions}

IK reviewed the literature and drafted the manuscript. NC helped to review the literature and draft the manuscript. TAM helped to conceptualize and draft the manuscript. All authors read and approved the final manuscript.

\section{Author details}

${ }^{1}$ Department of Psychiatry, Howard University, 530 College St. NW Washington, DC 20060, USA. ²Department of Neuroscience, Georgetown University, Washington, DC, USA.

Received: 25 November 2012 Accepted: 27 December 2012 Published: 31 December 2012

\section{References}

1. American Psychiatric Association: Diagnostic and Statistical Manual of Mental Disorders. Forth edition - Text revisionth edition. American Psychiatric Association: Washington, DC; 2000:2.

2. Kessler RC, Sonnega A, Bromet E, Hughes M, Nelson CB: Posttraumatic stress disorder in the national comorbidity survey. Arch Gen Psychiatry 1995, 52:1048-1060.

3. Tarrier N, Gregg L: Suicide risk in civilian PTSD patients. Soc Psychiatry Psychiatr Epidemiol 2004, 39:655-661.

4. Boscarino JA: A prospective study of PTSD and early-age heart disease mortality among Vietnam veterans: Implications for surveillance and prevention. Psychosom Med 2008, 70:668-676

5. Sareen J, Cox BJ, Stein MB, Afifi TO, Fleet C, Asmundson GJG: Physical and mental comorbidity, disability, and suicidal behavior associated with posttraumatic stress disorder in a large community sample. Psychosom Med 2007, 69:242-248.

6. Breslau N, Kessler RC, Chilcoat HD, Schultz LR, Davis GC, Andreski P: Trauma and posttraumatic stress disorder in the community: The 1996 Detroit area survey of trauma. Arch Gen Psychiatry 1998, 55:626-632.

7. Tolin DF, Foa EB: Sex differences in trauma and posttraumatic stress disorder: A quantitative review of 25 years of research. Psychol Bull 2006, 132:959-992.

8. Vrana S, Lauterbach D: Prevalence of traumatic events and post-traumatic psychological symptoms in a nonclinical sample of college students. J Trauma Stress 1994, 7:289-302.

9. Vogt D, Vaughn R, Glickman ME, Schultz M, Drainoni M-L, Elwy R, Eisen S: Gender differences in combat-related stressors and their association with postdeployment mental health in a nationally representative sample of U.S. OEF/OIF veterans. J Abnorm Psychol 2011, 120:797-806.

10. Hoge CW, Clark JC, Castro CA: Commentary: Women in combat and the risk of post-traumatic stress disorder and depression. Int J Epidemiol 2007, 36:327-329.

11. Olff M, Langeland W, Draijer N, Gersons BPR: Gender differences in posttraumatic stress disorder. Psychol Bull 2007, 133:183-204.

12. Cappuccio FP, D'Elia L, Strazzullo P, Miller MA: Sleep duration and all-cause mortality: A systematic review and meta-analysis of prospective studies. Sleep 2010, 33:585-592.

13. Ayas NT, White DP, Manson JE, Stampfer MJ, Speizer FE, Malhotra A, Hu FB: A prospective study of sleep duration and coronary heart disease in women. Arch Intern Med 2003, 163:205-209.

14. Patel SR, Hu FB: Short sleep duration and weight gain: A systematic review. Obesity 2008, 16:643-653.

15. Majde JA, Krueger JM: Links between the innate immune system and sleep. J Allergy Clin Immunol 2005, 116:1188-1198.

16. Krueger JM, Majde JA, Obál F Jr: Sleep in host defense. Brain Behav Immun 2003, 17:41-47.

17. Irwin MR, Wang M, Campomayor CO, Collado-Hidalgo A, Cole S: Sleep deprivation and activation of morning levels of cellular and genomic markers of inflammation. Arch Intern Med 2006, 166:1756-1762.

18. Vgontzas AN, Zoumakis E, Bixler EO, Lin H-M, Follett H, Kales A, Chrousos GP: Adverse effects of modest sleep restriction on sleepiness, performance, and inflammatory cytokines. J Clin Endocrinol Metab 2004, 89:2119-2126.
19. Alberti A, Sarchielli P, Gallinella E, Floridi A, Floridi A, Mazzotta G, Gallai V: Plasma cytokine levels in patients with obstructive sleep apnea syndrome: A preliminary study. J Sleep Res 2003, 12:305-311.

20. Breslau N, Roth T, Rosenthal L, Andreski P: Sleep disturbance and psychiatric disorders: a longitudinal epidemiological study of young adults. Biol Psychiatry 1996, 39:411-418.

21. Perlman CA, Johnson SL, Mellman TA: The prospective impact of sleep duration on depression and mania. Bipolar Disord 2006, 8:271-274.

22. Cho H, Lavretsky H, Olmstead R, Levin M, Oxman M, Irwin M: Sleep disturbance and depression recurrence in community-dwelling older adults: A prospective study. Am J Psychiatry 2008, 165:1543-1550.

23. Dew MA, Reynolds CF III, Houck PR, Hall M, Buysse DJ, Frank E, Kupfer DJ: Temporal profiles of the course of depression during treatment: Predictors of pathways toward recovery in the elderly. Arch Gen Psychiatry 1997, 54:1016-1024.

24. Cartwright $R$, Young MA, Mercer $P$, Bears M: Role of REM sleep and dream variables in the prediction of remission from depression. Psychiatry Res 1998, 80:249-255.

25. Neylan TC, Marmar CR, Metzler TJ, Weiss DS, Zatzick DF, Delucchi KL Wu RM, Schoenfeld FB: Sleep disturbances in the Vietnam generation: Findings from a nationally representative sample of male Vietnam veterans. Am J Psychiatry 1998, 155:929-933.

26. Ohayon MM, Shapiro CM: Sleep disturbances and psychiatric disorders associated with posttraumatic stress disorder in the general population. Compr Psychiatry 2000, 41:469-478.

27. Rothbaum BO, Foa EB, Riggs DS, Murdock T, Walsh W: A prospective examination of post-traumatic stress disorder in rape victims. J Trauma Stress 1992, 5:455-475.

28. Foa EB, Riggs DS, Gershuny BS: Arousal, numbing, and intrusion: symptom structure of PTSD following assault. Am J Psychiatry 1995, 152:116-120.

29. Koren D, Arnon I, Lavie P, Klein E: Sleep complaints as early predictors of posttraumatic stress disorder: A 1-Year prospective study of injured survivors of motor vehicle accidents. Am J Psychiatry 2002, 159:855-857.

30. Bryant RA, Creamer M, O'Donnell M, Silove D, McFarlane AC: Sleep disturbance immediately prior to trauma predicts subsequent psychiatric disorder. Sleep 2010, 33:69-74.

31. Kobayashi I, Sledjeski EM, Spoonster E, Fallon WF, Delahanty DL: Effects of early nightmares on the development of sleep disturbances in motor vehicle accident victims. J Trauma Stress 2008, 21:548-555.

32. Mellman TA, David D, Bustamante V, Torres J, Fins A: Dreams in the acute aftermath of trauma and their relationship to PTSD. J Trauma Stress 2001, 14:241-247.

33. Kobayashi I, Boarts JM, Delahanty DL: Polysomnographically measured sleep abnormalities in PTSD: a meta-analytic review. Psychophysiology 2007, 44:660-669.

34. Lavie P: Sleep disturbances in the wake of traumatic events. N Engl J Med 2001, 345:1825-1832.

35. Kobayashi I, Huntley E, Lavela J, Mellman TA: Subjectively and objectively measured sleep with and without posttraumatic stress disorder and trauma exposure. Sleep 2012, 35:957-965.

36. Calhoun PS, Wiley M, Dennis MF, Means MK, Edinger JD, Beckham JC: Objective evidence of sleep disturbance in women with posttraumatic stress disorder. J Trauma Stress 2007, 20:1009-1018.

37. Hurwitz TD, Mahowald MW, Kuskowski M, Engdahl BE: Polysomnographic sleep is not clinically impaired in Vietnam combat veterans with chronic posttraumatic stress disorder. Biol Psychiatry 1998, 44:1066-1073.

38. Breslau N, Roth T, Burduvali E, Kapke A, Schults L, Roehrs T: Sleep in lifetime posttraumatic stress disorder a community-based polysomnographic study. Arch Gen Psychiatry 2004, 61:508-516

39. Habukawa M, Uchimura N, Maeda M, Kotorii N, Maeda H: Sleep findings in young adult patients with posttraumatic stress disorder. Biol Psychiatry 2007, 62:1179-1182.

40. Mellman TA, Bustamante V, Fins Al, Pigeon WR, Nolan B: REM sleep and the early development of posttraumatic stress disorder. Am J Psychiatry 2002, 159:1696-1701.

41. Woodward SH, Murburg MM, Bliwise DL: PTSD-related hyperarousal assessed during sleep. Physiol Behav 2000, 70:197-203.

42. Germain A, Hall M, Katherine Shear M, Nofzinger EA, Buysse DJ: Ecological study of sleep disruption in PTSD: A pilot study. Ann N Y Acad Sci 2006, 1071:438-441. 
43. Perlis ML, Smith MT, Andrews PJ, Orff H, Giles DE: Beta/gamma EEG activity in patients with primary and secondary insomnia and good sleeper controls. Sleep 2001, 24:110-117.

44. Buysse DJ, Germain A, Hall ML, Moul DE, Nofzinger EA, Begley A, Ehlers CL, Thompson W, Kupfer DJ: EEG spectral analysis in primary insomnia: NREM period effects and sex differences. Sleep 2008, 31:1673-1682.

45. Cohen DJ, Begley A, Alman JJ, Cashmere DJ, Pietrone RN, Seres RJ, Germain A: Quantitative electroencephalography during rapid eye movement (REM) and non-REM sleep in combat-exposed veterans with and without posttraumatic stress disorder. J Sleep Res 2012.

46. Mellman TA, Pigeon WR, Nowell PD, Nolan B: Relationships between REM sleep findings and PTSD symptoms during the early aftermath of trauma. J Trauma Stress 2007, 20:893-901.

47. Sanford LD, Tang X, Ross RJ, Morrison AR: Influence of shock training and explicit fear-conditioned cues on sleep architecture in mice: strain comparison. Behav Genet 2003, 33:43-58.

48. Tang $X$, Yang L, Sanford LD: Rat strain differences in freezing and sleep alterations associated with contextual fear. Sleep 1995, 28:1235-1244.

49. Adrien J, Dugovic C, Martin P: Sleep-wakefulness patterns in the helpless rat. Physiol Behav 1991, 49:257-262.

50. Palma BD, Suchecki D, Tufik S: Differential effects of acute cold and footshock on the sleep of rats. Brain Res 2000, 861:97-104.

51. Jha SK, Brennan FX, Pawlyk AC, Ross RJ, Morrison AR: REM sleep: A sensitive index of fear conditioning in rats. Eur J Neurosci 2005, 21:1077-1080.

52. Pawlyk AC, Jha SK, Brennan FX, Morrison AR, Ross RJ: A rodent model of sleep disturbances in posttraumatic stress disorder: the role of context after fear conditioning. Biol Psychiatry 2005, 57:268-277.

53. Sanford LD, Fang J, Tang $X$ : Sleep after differing amounts of conditioned fear training in BALB/cJ mice. Behav Brain Res 2003, 147:193-202.

54. Sanford LD, Yang $L$, Tang $X$ : Influence of contextual fear on sleep in mice: A strain comparison. Sleep 2003, 26:527-540.

55. DaSilva JK, Lei Y, Madan V, Mann GL, Ross RJ, Tejani-Butt S, Morrison AR: Fear conditioning fragments REM sleep in stress-sensitive Wistar-Kyoto, but not Wistar, rats. Prog Neuro-Psychopharmacol Biol Psychiatry 2011, 35:67-73.

56. Jaussent I, Dauvilliers Y, Ancelin M-L, Dartiques J, Tavernier B, Touchon J, Ritchie K, Besset A: Insomnia symptoms in older adults: associated factors and gender differences. Am J Geriatr Psychiatry 2011, 19:88-97.

57. Groeger JA, Zijlstra FRH, Dijk DJ: Sleep quantity, sleep difficulties and their perceived consequences in a representative sample of some 2000 British adults. J Sleep Res 2004, 13:359-371.

58. Lindberg E, Janson C, Gislason T, Bjornsson E, Hetta J, Boman G: Sleep disturbances in a young adult population: Can gender differences be explained by differences in psychological status? Sleep 1997, 20:381-387.

59. Schredl M, Reinhard I: Gender differences in nightmare frequency: A meta-analysis. Sleep Med Rev 2011, 15:115-121.

60. Redline S, Kirchner HL, Quan SF, Gottlieb DJ, Kapur V, Newman A: The effects of age, sex, ethnicity, and sleep-disordered breathing on sleep architecture. Arch Intern Med 2004, 164:406-418.

61. Roehrs T, Kapke A, Roth T, Breslau N: Sex differences in the polysomnographic sleep of young adults: a community-based study. Sleep Med 2006, 7:49-53.

62. Mongrain V, Carrier J, Dumont M: Chronotype and sex effects on sleep architecture and quantitative sleep EEG in healthy young adults. Sleep 2005, 28:819-827.

63. Resta O, Caratozzolo G, Pannacciulli N, Stefano A, Giliberti T, Carpagnano GE, De Pergola G: Gender, age and menopause effects on the prevalence and the characteristics of obstructive sleep apnea in obesity. Eur J Clin Invest 2003, 33:1084-1089.

64. Manber R, Armitage R: Sex, steroids, and sleep: A review. Sleep 1999, 22:540-555.

65. Matsumoto AM, Sandblom RE, Schoene RB, Lee KA, Giblin EC, Pierson DJ, Bremner WJ: Testosterone replacement in hypogonadal men: Effects on obstractive sleep apnoea, respiratory drives, and sleep. Clin Endocrinol 1985, 22:713-721.

66. Liu PY, Yee B, Wishart SM, Jimenez M, Jung DG, Grunstein RR, Handelsman DJ: The short-term effects of high-dose testosterone on sleep, breathing, and function in older men. J Clin Endocrinol Metab 2003, 88:3605-3613.

67. Manber R, Bootzin RR: Sleep and the menstrual cycle. Health Psychol 1997, $16: 209-214$
68. Baker FC, Driver HS: Self-reported sleep across the menstrual cycle in young, healthy women. J Psychosom Res 2004, 56:239-243.

69. Shechter A, Varin F, Boivin DB: Circadian variation of sleep during the follicular and luteal phases of the menstrual cycle. Sleep 2010, 33:647-656

70. Driver HS, Dijk D, Werth E, Biedermann K, Borbély AA: Sleep and the sleep electroencephalogram across the menstrual cycle in young healthy women. J Clin Endocrinol Metab 1996, 81:728-735.

71. Parry BL, Mostofi N, LeVeau B, Nahum HC, Golshan S, Laughlin GA, Gillin JC: Sleep EEG studies during early and late partial sleep deprivation in premenstrual dysphoric disorder and normal control subjects. Psychiatry Res 1999, 85:127-143.

72. Ishizuka Y, Pollack CP, Shirakawa S, Kakuma T, Azumi K, Usui A, Shiraishi K, Fukuzawa H, Kariya T: Sleep spindle frequency changes during the menstrual cycle. J Sleep Res 1994, 3:26-29.

73. Lee KA, Shaver JF, Giblin EC, Woods NF: Sleep patterns related to menstrual cycle phase and premenstrual affective symptoms. Sleep 1990, 13:403-409.

74. Baker FC, Waner Jl, Vieira EF, Taylor SR, Driver HS, Mitchell D: Sleep and 24 hour body temperatures: a comparison in young men, naturally cycling women and women taking hormonal contraceptives. J Physiol 2001, 530:565-574

75. Paul KN, Dugovic C, Turek FW, Laposky AD: Diurnal sex differences in the sleep-wake cycle of mice are dependent on gonadal function. Sleep 2006, 29:1211-1223.

76. Fang J, Fishbein W: Sex differences in paradoxical sleep: influences of estrus cycle and ovariectomy. Brain Res 1996, 734:275-285.

77. Paul KN, Laposky AD, Turek FW: Reproductive hormone replacement alters sleep in mice. Neurosci Lett 2009, 463:239-243.

78. Koehl M, Battle SE, Turek FW: Sleep in female mice: A strain comparison across the estrous cycle. Sleep 2003, 26:267-272

79. Milad MR, Goldstein JM, Orr SP, Wedig MM, Klibanski A, Pitman RK, Rauch SL: Fear conditioning and extinction: Influence of sex and menstrual cycle in healthy humans. Behav Neurosci 2006, 120:1 196-1203.

80. Gupta RR, Sen S, Diepenhorst LL, Rudick CN, Maren S: Estrogen modulates sexually dimorphic contextual fear conditioning and hippocampal longterm potentiation (LTP) in rats. Brain Res 2001, 888:356-365.

81. Milad MR, Pitman RK, Ellis CB, Gold AL, Shin LM, Lasko NB, Zeidan MA, Handwerger K, Orr SP, Rauch SL: Neurobiological basis of failure to recall extinction memory in posttraumatic stress disorder. Biol Psychiatry 2009, 66:1075-1082

82. Germain A, Buysse DJ, Shear MK, Fayyad R, Austin C: Clinical correlates of poor sleep quality in posttraumatic stress disorder. J Trauma Stress 2004 17:477-484.

83. Ulmer CS, Sutherland M, Edinger JD, Davidson J, Connor KM, Zhang W, Krystal A: REM sleep bout duration and frequency in PTSD. J Aggression Maltreat Trauma 2012, 21:67-76.

84. Kobayashi I, Mellman TA: Gender differences in sleep during the aftermath of trauma and the development of posttraumatic stress disorder. Behav Sleep Med 2012, 10:180-190.

85. Otte C, Lenoci M, Metzler T, Yehuda R, Marmar CR, Neylan TC: Effects of metyrapone on hypothalamic-pituitary-adrenal axis and sleep in women with post-traumatic stress disorder. Biol Psychiatry 2007, 61:952-956.

doi:10.1186/2042-6410-3-29

Cite this article as: Kobayashi et al:: One's sex, sleep, and posttraumatic stress disorder. Biology of Sex Differences 2012 3:29. 